\title{
The Mechanical and Brittle Properties of Gas Pipeline in Service ${ }^{\dagger}$
}

\author{
M. Hagarová*, J. Cervová, M. Fujda, M. Mihaliková and A. Lišková \\ Institute of Materials, Faculty of Metallurgy, Technical University of Košice, 04200 Košice, Slovakia \\ (Received September 11, 2016; in final form July 4, 2017)
}

\begin{abstract}
The paper deals with the determination of mechanical and brittle properties of gas pipeline after more than 40 years in operation. The heat affected zone in weld of pipeline is the risk area in terms of embrittlement structure, which resulted in an increase of yield strength and shift of transit temperature to more positive values. The specimens were cut from heat affected zone for this reason. The tensile test according to ISO 6892-1 showed the increase in yield strength: it had a value of $295 \mathrm{MPa}$ at the beginning operation and $400 \mathrm{MPa}$ after more than 40 years in pipeline operation was recorded. The transition temperature at the value of $20^{\circ} \mathrm{C}$ was determined by using the Charpy impact test according to EN 10045-1. The operators of gas pipelines report that the mean temperature on the outer surface of pipe is about $4{ }^{\circ} \mathrm{C}$ during the winter. The risk of brittle fragile is very likely if the transition temperature is higher than operating temperature.
\end{abstract}

DOI: 10.12693/APhysPolA.132.1238

PACS/topics: pipeline, steel, tensile test, Charpy impact test

\section{Introduction}

Natural gas is the most utilised source of energy in Slovakia and its production constantly increases [1]. Gas is transported across Slovakia using transit system of length of approximately $2270 \mathrm{~km}$. Gas distribution network of length of almost $33000 \mathrm{~km}$ is connected to this transit system. The history of the building of the first line of transit system goes back to the seventies of the 20th century [2]. Steel is most frequently used construction material gas pipelines. The extensive use of steel for this purpose is based mostly on its good availability and low cost. The current trend in the development of gas distribution network focuses not only on prolongation of service life of the in-service pipelines but also on maintenance of operation safety of this structure. A number of factors affects the safety and reliability of gas pipelines, among them the way of laying down the pipes, operating conditions, mechanical stress related to changes in environmental conditions, corrosive aggressiveness of soil, climate (changes in temperature and water content of soil) and others $[3,4]$. Therefore, it is important to know not only the condition of the steel pipes surface but also their mechanical and brittle-fracture properties resulting from changes in their structure. Ageing of steels is a consequence of interstitial nitrogen redistribution and partially also of carbon in $\mathrm{Fe}_{\alpha}$. Ageing of steel causes changes in strength properties and deformation characteristics potentially leading to pronounced embrittlement. The yield point, then, increases and reaches values close to the brit-

\footnotetext{
*corresponding author; e-mail: maria.hagarova@tuke.sk
}

†paper contributed to the 11th Polish-Japanese Joint Seminar on Micro and Nano Analysis, Gniew, Poland, September 11-14, 2016 tle strength. The notch sensitivity also increases and transition temperature of notch toughness shifts toward positive values [5-7].

\section{Experimental material and methods}

Mechanical properties of specimens of steel P295GH (in wt\%: $0.17 \mathrm{C}, 1.08 \mathrm{Mn}, 0.25 \mathrm{Si}, 0.028 \mathrm{P}, 0.038 \mathrm{~S}$ ) were determined by tensile test using an equipment ZWICK 1387 at temperature $20 \pm 3{ }^{\circ} \mathrm{C}$ and machine loading range of $F=0 \div 200 \mathrm{kN}$. Test rods of dimensions $d_{0}=5 \mathrm{~mm}$ and $L_{0}=10 \mathrm{~mm}$ were broken at a testing speed of $1 \mathrm{~mm} \mathrm{~min}{ }^{-1}$. Mechanical properties of steel (yield strength $R_{e}$, tensile strength $R_{m}$ and ductility $A_{5}$ ) were determined on specimens cut perpendicular $(\mathrm{T})$ to the pipe longitudinal axis. The test was carried out according to EN ISO 6892-1 [8]. The Charpy impact test for determination of brittle fracture properties of gas pipes was carried out using a Charpy pendulum according to EN 10045-2. The principle of this test is based on breaking the test specimen under conditions specified by EN 10045-1 and EN 10045-2 [9, 10]. The test was conducted in temperature intervals: from $-20^{\circ} \mathrm{C}$ to $+20^{\circ} \mathrm{C}-$ on the basis of report of gas pipelines operators, that in winter months the mean temperature on the outer surface of pipe is about $4{ }^{\circ} \mathrm{C}$ [11]. Fracture surfaces of specimens of the Charpy test were examined by electron microscope JEOL JSM-7000F. Criterion of impact energy $K=27 \mathrm{~J}$ was used to determine transition temperature of steel in heat affected zone (HAZ). The value of impact energy $K$ was established according to the standard EN ISO 148-1 [12].

\section{Results and discussion}

Table I shows mechanical properties of steel specimens cut in the longitudinal axis of the pipe, which reached the 
following values: $R_{e}=400 \mathrm{MPa}, R_{m}=649 \mathrm{MPa}, A_{5}=$ $18 \%$. Strength characteristics increased during operation of pipes, particularly the yield strength, in comparison with the standardized values, as shown in Table I. The structure of steel in HAZ area has been changed during the welding operation on gas pipelines, too.

TABLE I

Mechanical characteristics of in-service steel pipeline. Sample T5, perpendicular to longitudinal pipe axis and requirements of EN 10028/2-92

\begin{tabular}{c|c|c|c}
\hline \hline & $R_{e}\left(R_{p 0,2}\right)[\mathrm{MPa}]$ & $R_{m}[\mathrm{MPa}]$ & $A_{5}[\%]$ \\
\hline T5 & 400 & 649 & 18.0 \\
EN 10028/2-92 & 295 & $460-580$ & min 22.0
\end{tabular}

This process is accompanied by increased strength of the material. The ageing process was very likely going in steel structure during long-term operation of pipeline and led to another increase in strength. The precipitates were detected by means of transmission electron microscopy on the basis iron carbide in HAZ area, see Fig. 1.

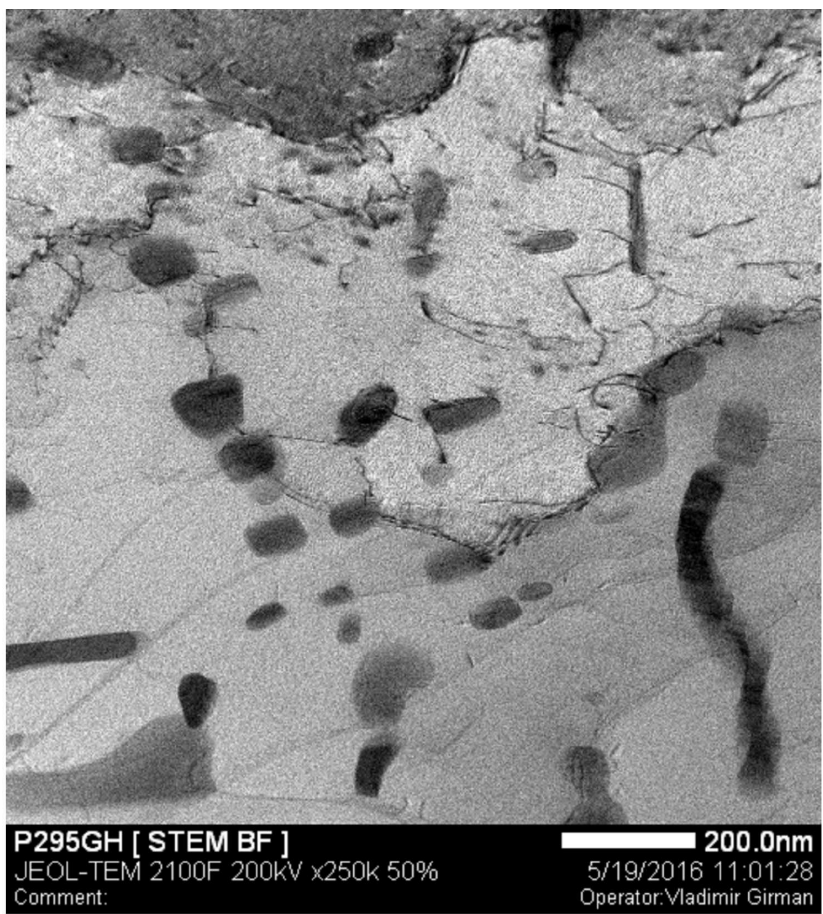

Fig. 1. Iron carbides particles on the dislocations, TEM.

The measurement of selected reflections proved that the distance $4.11 \mathrm{~nm}^{-1}$ or $4.82 \mathrm{~nm}^{-1}$, as the case may be, correspond to the $\mathrm{Fe}_{3} \mathrm{C}(210)$ and $(-220)$ in the reciprocal space, see Fig. 2. Precipitates of this size could be effective barriers to the movement of dislocations and contributed to strengthening of the structure [12].

Results of the Charpy test are presented in Table II. According to the criterion of impact energy $K=27 \mathrm{~J}$, transition temperature was determined; in our case it reached the transition temperature value of $T_{t}=+20^{\circ} \mathrm{C}$. Results from the technical practice indicated that it is

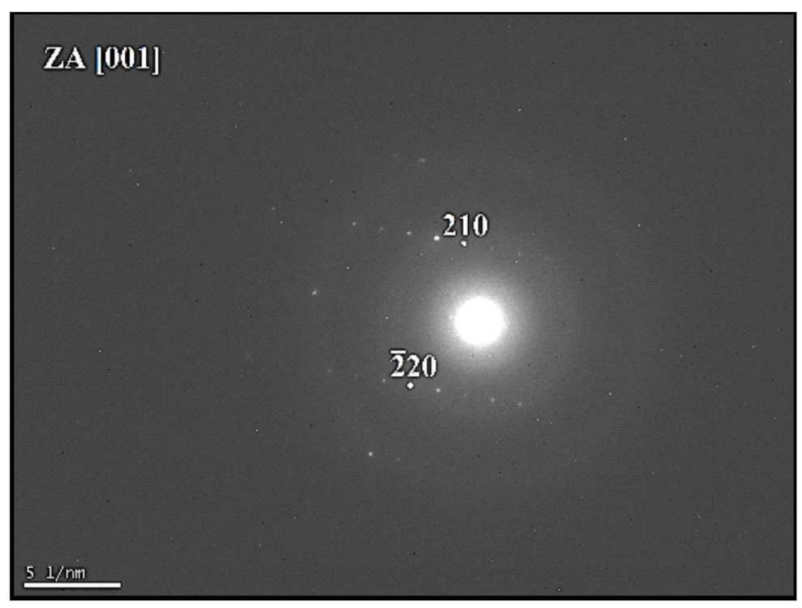

Fig. 2. Diffractogram of iron carbide, TEM.

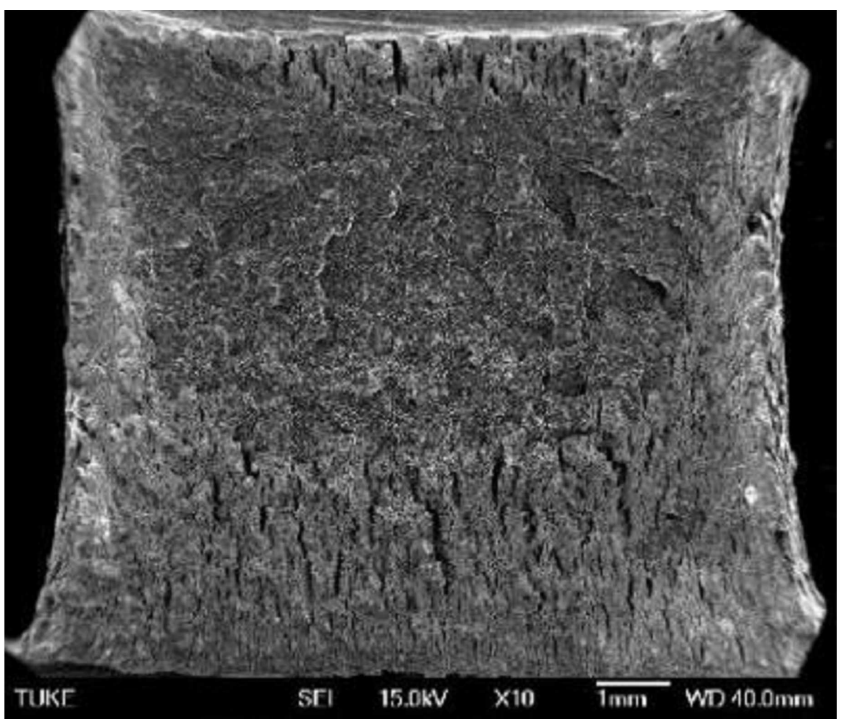

Fig. 3. Fracture surface of specimen W03; $K=27 \mathrm{~J}$.

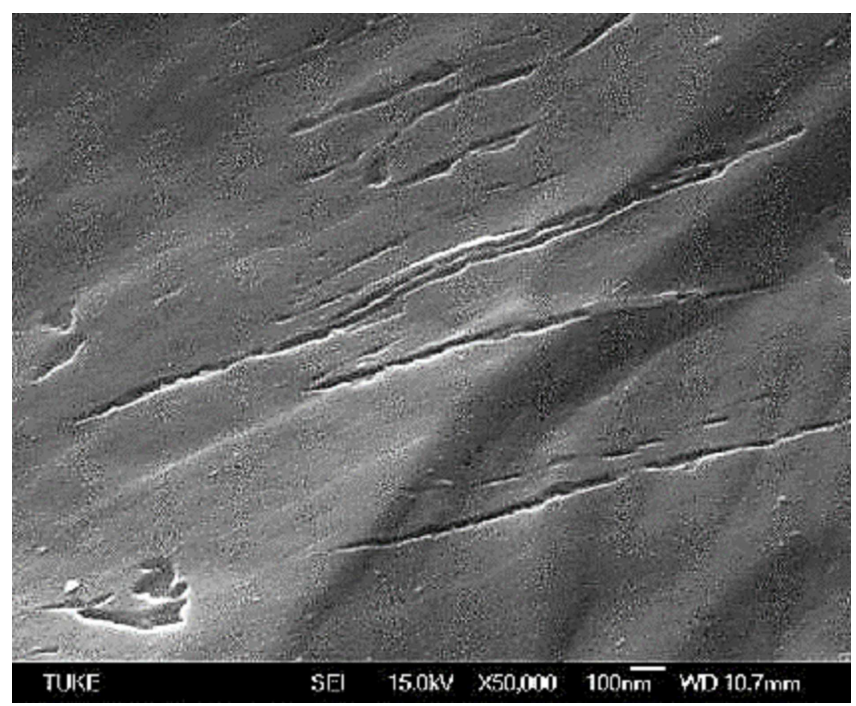

Fig. 4. Cavities on the surface of the sample W03. 
Results of the Charpy impact test

TABLE II

\begin{tabular}{c|c|c|c|c|c|c|c|c|c|c|c|c}
\hline \hline & W01 & W02 & W03 & W04 & W05 & W06 & W07 & W08 & W09 & W10 & W11 & W12 \\
\hline$T\left[{ }^{\circ} \mathrm{C}\right]$ & +20 & +20 & +20 & 0 & 0 & 0 & -10 & -10 & -10 & -20 & -20 & -20 \\
$K[\mathrm{~J}]$ & 24 & 23 & 27 & 16 & 20 & 20 & 14 & 16 & 17 & 13 & 14 & 14
\end{tabular}

important to ensure that the material is loaded at temperatures above $T_{t}$. In our study the analysis of the character of fracture surfaces after the Charpy testing was carried out on specimens fractured at $+20^{\circ} \mathrm{C}, 0^{\circ} \mathrm{C}$ and $-10^{\circ} \mathrm{C}$, i.e. in the temperature range, where there was a transition temperature.

Analysis of fracture surface of specimen W03, documented in Fig. 3, obtained by fracture of the specimen at the Charpy test conducted at $+20^{\circ} \mathrm{C}$, showed a mixed character of failure. Transcrystalline brittle failure was located in the middle of the fracture area. Transcrystalline ductile failure was situated in the lower part of the specimen. Cavity size with inclusions was larger than others, Fig. 4. Separation of inclusions has created cracks on the cavity walls [13].

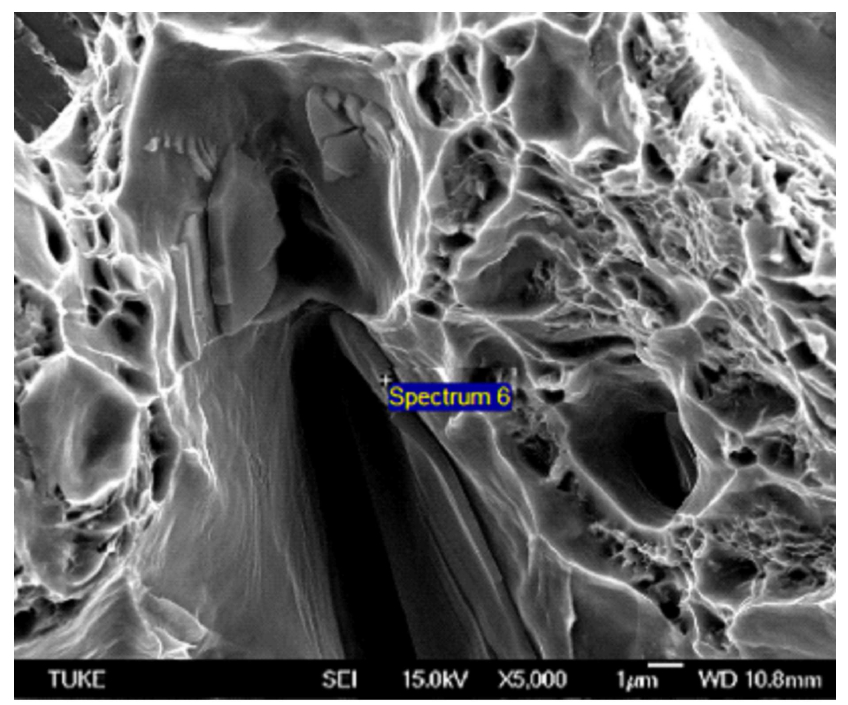

Fig. 5. Fracture surface with particles, SEM.

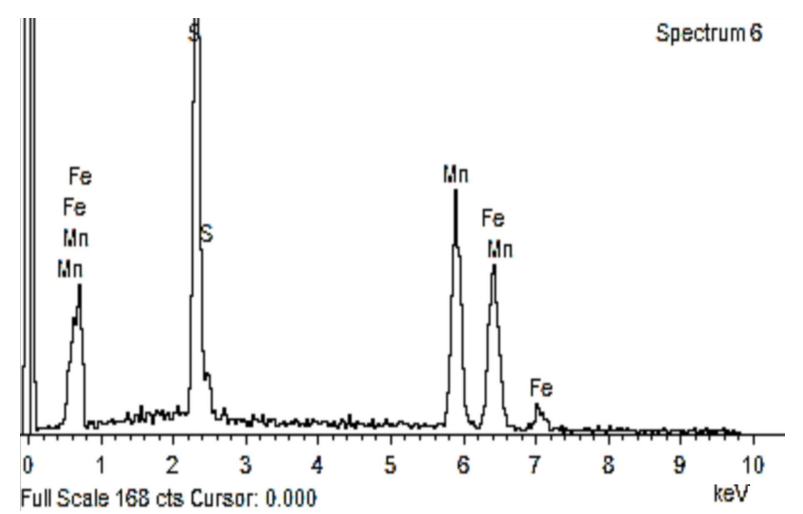

Fig. 6. EDX spectrum of the particles.

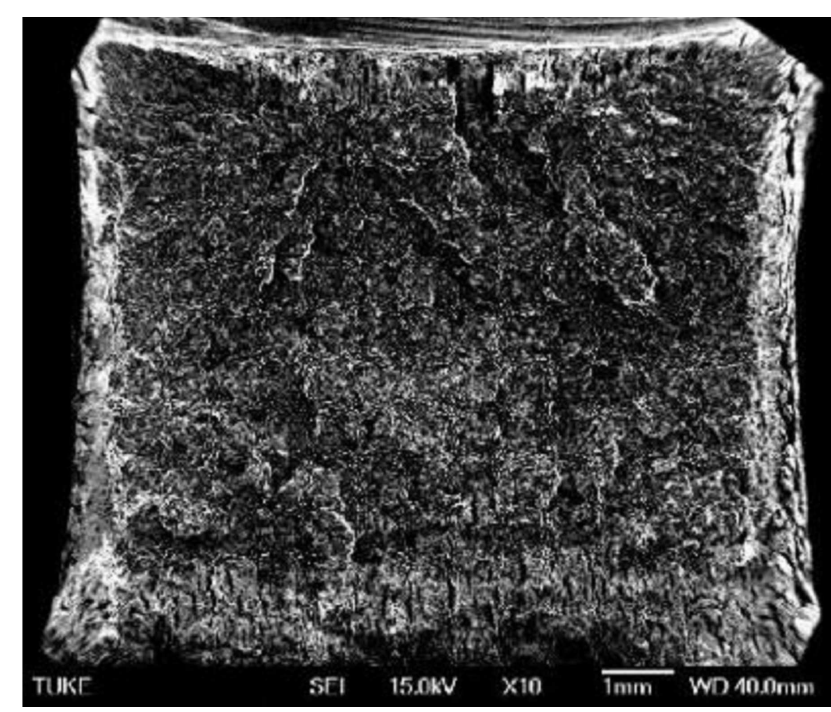

Fig. 7. Fracture surface of specimen W05; $K=20 \mathrm{~J}$.

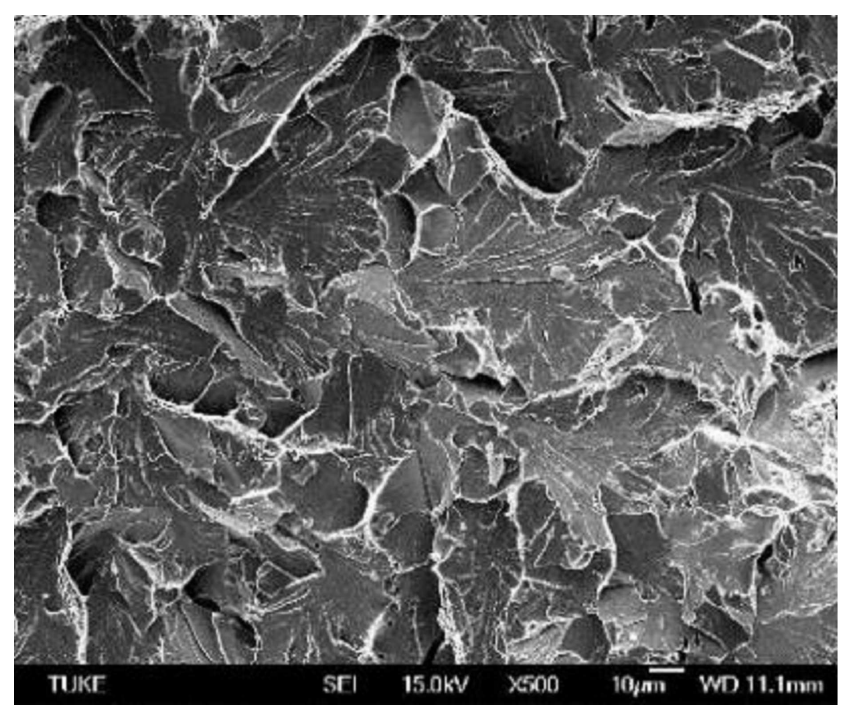

Fig. 8. Transcrystalline brittle failure of fracture surface of sample W05.

The transgranular ductile fracture areas were located at the bottom of these samples. The inclusions were observed in the wells of grain, see Fig. 5. It is possible to observe particles which were identified by energy dispersive X-ray (EDX) analysis, Fig. 6, by scanning electron microscope as sulphides of manganese and iron in the walls of ductile failure shown in Fig. 5: MnS respectively $\mathrm{MnFeS}$ [14].

Figure 7 shows fracture surface of specimen W05 broken at $0^{\circ} \mathrm{C}$. The fracture surface shows minor proportion of transcrystalline ductile failure. The edges of holes of transgranular ductile fracture were slightly rounded which corresponds to higher values of plastic deformation. The presence of facets was the evidence of intergranular brittleness of ferrite. This was formed mainly 


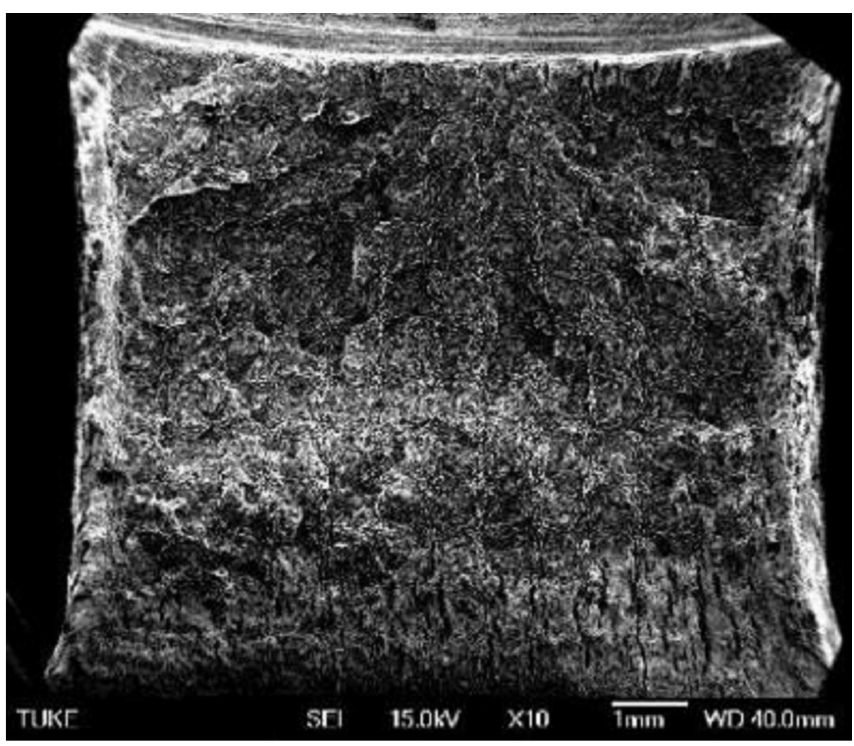

Fig. 9. Fracture surface of specimen W07; $K=14 \mathrm{~J}$.

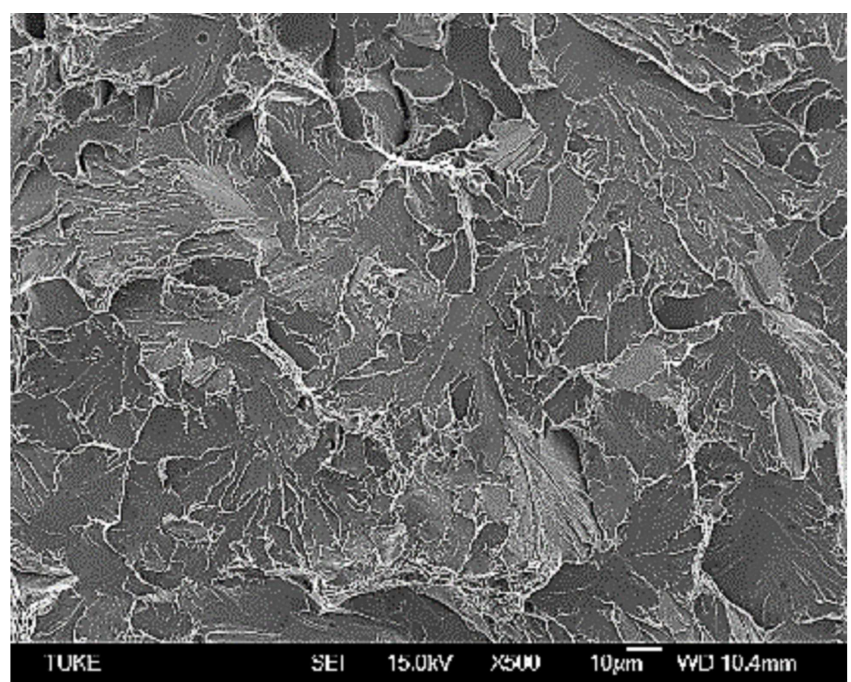

Fig. 10. Transcrystalline brittle failure of fracture surface of sample W07.

as a result of segregation of impurity atoms at the grain boundaries. The specimen edges were little deformed. The cleavage facets of transcrystalline fracture formed major proportion of fracture surface. Figure 8 shows transcrystalline brittle failure of fracture surface of specimen W05.

Figure 9 shows fracture surface of specimen W07, fractured at $-10^{\circ} \mathrm{C}$. The character of failure was mixed and the major proportion of fracture surface showed transcrystalline brittle failure, Fig. 10. The brittle and plastic ones (area with pitted surface morphology) were in both areas of failure.

\section{Conclusion}

The gas pipeline consists of pipes, which were welded together. The structure changes during welding process affected mechanical properties of steel in joints. Steel pipeline is a subject of natural ageing phenomenon which is likely to be accelerated by the service conditions.

Analysis of mechanical and brittle fracture properties of steel P295 GH was carried out for the purpose of evaluation of the condition of pipeline after more than 40 years of its service. The tests conducted during our study allowed us to state the following:

- The static tensile test revealed increase in the values of strength characteristics, particularly the yield strength, during pipeline operation.

- The other increase of strength could be caused by ageing process. The precipitation of fine carbides on the dislocations networks led to originating stronger interactions and created a barrier for their movement thus resulting in additional strength of the final microstructure.

- The decrease of ductility led to shift of transit temperature to more positive values. The presence of transcrystalline brittle fracture has been identified on the fracture surface on the specimen broken at the temperature of $20^{\circ} \mathrm{C}$.

- The average operating temperature of the pipeline is $4{ }^{\circ} \mathrm{C}$ in winter months and thus this finding out is risky from the perspective of further operation of the pipeline.

\section{References}

[1] J. Ferrier, Slovgas 22, 5 (2013).

[2] J. Grňo, Corrosion of Underground Structures, Košice, 2003, p. 1.

[3] J.A. Beavers, G.T. Neil, ASM Handbook, Eds. S.D. Cramer, B.S. Covino, ASM International, Ohio 2006, p. 1015.

[4] I.S. Cole, D. Marney, Corrosion Science 56, 5 (2012).

[5] A. Li, W. Wang, X. Wang, D. Zhao, Eng. Fail. Anal. 12, 4 (2005).

[6] B. Vargas-Arista, A. Albiter, F. García-Vázquez, Ó. Mendoza-Camargo, J.M. Hallen, Rev. Met. 50, e024 (2014).

[7] H. Nykyforchyn, E. Lunarska, O. Tsyrulnyk, K. Nikiforov, G. Gabetta, Mater. Corros. 60, 9 (2009).

[8] EN ISO 6892-1:2009 Metallic materials. Tensile testing. Part 1: Method of test at ambient temperature.

[9] EN 10045-2:1993 Charpy impact test on metallic materials. Part 2: Method for the verification of impact testing machines.

[10] EN 10045-1:1990 Metallic materials. Charpy impact test. Part 1: Test method.

[11] Internal information for Slovak Gas Industry - distribution, a.s., (in Slovak).

[12] EN ISO 148-1:2009 Metallic materials - Charpy pendulum impact test. Part 1: Test method.

[13] M. Sohaciu, C. Pradescu, E. Vasile, E. Matei, D. Savastru, A. Berbecaru, Digest J. Nanomater. Biostruct. 8, 1 (2013).

[14] A.I. Zaky Farahat, A.M. Bahgat Gemeal, R.N. Elshaer, J. Fail. Anal. Preven. 16, 86 (2016). 